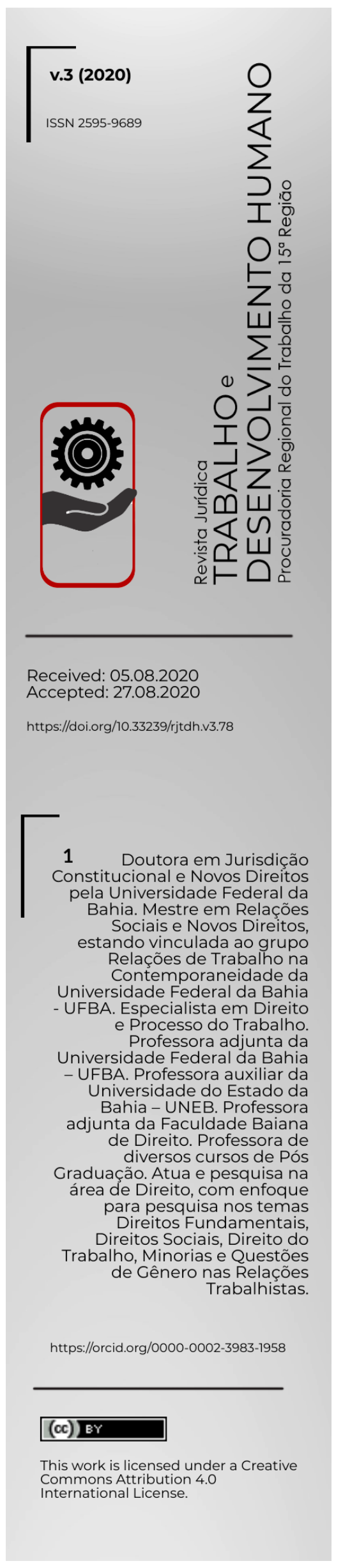

\title{
Coronavírus e a farsa da liberdade negocial nos acordos individuais entre empregados e empregadores
}

\author{
Coronavirus and the farce of negotiation freedom in individual agreements \\ between employees and employers \\ Coronavirus y la farsa de la libertad negocial en acuerdos individuales entre \\ empleados y empleadores
}

Adriana Brasil Vieira Wyzykowski ${ }^{1}$

RESUMO

A vulnerabilidade do empregado no exercício da sua liberdade negocial individual relaciona-se diretamente com direitos de liberdade e igualdade, condensando o feixe de estudo da autonomia privada. Em tempos de pandemia pelo COVID-19, a vulnerabilidade do empregado apodera-se de forma agravada, em face de um desequilíbrio ainda mais notório nas relações jurídicas empregatícias. O autorregramento da vontade e a criação de normas jurídicas individuais, no entanto, foi privilegiado pelas Medidas Provisórias 927, já inválida, e 936, convertida na Lei $14.020 / 20$, ao afirmarem a força dos acordos individuais trabalhistas. Concluiu-se que estas normas individuais ofendem a rede de proteção social do trabalho ante a pantomima da liberdade negocial, que acentua o domínio da vontade dos empregados pelo receio de desemprego e poderes do empregador, além de promover o esvaziamento da autonomia privada coletiva, numa precarização da entidade sindical.

PALAVRAS-CHAVE: Coronavírus. Contrato de trabalho. Liberdade negocial individual. Farsa da autonomia do empregado.

\section{ABSTRACT}

The employee's vulnerability in the exercise of his individual negotiation freedom is directly related to the rights of freedom and equality, condensing the bundle of study of private autonomy. In times of pandemic by COVID-19, the employee's vulnerability takes hold in an aggravated way, in the face of an even more notorious imbalance in legal employment relations. Self-reassignment of the will and the creation of individual legal rules, however, was privileged by Provisional Measures 927, already invalid, and 936, converted into law 14.020/20, when affirming the strength of individual labor agreements. It was concluded that these individual rules offend the social protection of work in the face of the pantomime of negotiation freedom, which accentuates the domination of the will of the employees due to fear of unemployment and the employer's powers, besides promoting the emptying of collective private autonomy, in a precariousness of the union entity.

KEYWORDS: Coronavirus. Employment contract. Individual negotiation freedom. Farce of employee autonomy.

\section{RESUMEN}

La vulnerabilidad del empleado en el ejercicio de su libertad empresarial individual está directamente relacionada con los derechos de libertad e igualdad, condensando el haz de estudio de la autonomía privada. En tiempos de pandemia por COVID-19, la vulnerabilidad del empleado se agrava, ante un desequilibrio aún más notorio en las relaciones laborales legales. La autoreasignación de la voluntad y la creación de normas jurídicas individuales, sin embargo, fueron favorecidas por las Medidas Provisionales 927, ya inválida, y 936, convertida en Ley 14.020/20, al afirmar la solidez de los acuerdos laborales individuales. Se concluyó que estas normas individuales atentan contra la red de protección social del trabajo frente a la pantomima de la libertad empresarial, que acentúa el dominio de la voluntad de los empleados por temor al desempleo y a los poderes patronales, además de promover el vaciamiento de la autonomía privada colectiva, en un precariedad de la entidad sindical.

PALABRAS CLAVE: Coronavirus. Contrato de trabajo. Libertad empresarial individual. Farsa de autonomía de los empleados. 
Revista Jurídica Trabalho e Desenvolvimento Humano Procuradoria Regional do Trabalho da 15a Região

Introdução

O Brasil vive um grave momento de crise sanitária em face da propagação do coronavírus (COVID-19). O estado de calamidade pública, reconhecido no Decreto Legislativo 6/2020, bem como o estabelecimento de medidas de enfrentamento previstas pela Lei $13.979 / 20$, como isolamento e quarentena, demonstram a severidade e o perigo causados pelo novo vírus.

A pandemia acaba por desvelar a necessidade urgente de regulação do trabalho, trazendo desafios dentre o caos e incertezas da situação. Sabe-se que, enquanto não houver vacina ou medicamento adequado, a única solução para o enfrentamento deste momento é o chamado distanciamento social, que implica em uma mudança de paradigmas e comportamentos a nível mundial e nacional.

Questões relacionadas à manutenção dos postos de trabalho diante das atividades econômicas que estão paralisadas ou que tiveram diminuição sensível, bem como proteção àqueles que se encontram na informalidade passaram a fazer parte do cotidiano brasileiro, ensejando reflexões acerca do sistema de proteção social do trabalho.

Inicialmente foi publicada a Medida Provisória (MP) 927, de 22 de março de 2020, com o fulcro de estabelecer medidas trabalhistas para a preservação do emprego e renda, medida provisória esta que caducou em 19 de julho de 2020. Esta MP considerou que o estado de calamidade pública deveria ser encarado como hipótese de força maior, conforme o art. 1으, parágrafo único. Posteriormente, em primeiro de abril de 2020 entrou em vigor a Medida Provisória 936, convertida na Lei 14.020/20, com o objetivo de implementar o chamado Programa Emergencial de Manutenção do Emprego e da Renda, além de trazer outras medidas trabalhistas complementares para o enfrentamento do estado de calamidade pública e de emergência sanitária decorrente do coronavírus.

Estas normas possuem em comum o enfoque à autonomia privada individual trabalhista, estabelecendo a possibilidade de acordos individuais celebrados entre empregados e empregadores, que irão, inclusive, prevalecer sobre os instrumentos coletivos. Este artigo se dispõe a tratar da farsa da autonomia privada individual estabelecida em tempos

WYZYKOWSKI, Adriana Brasil Vieira. Coronavírus e a farsa da liberdade negocial nos acordos individuais entre empregados e empregadores. Revista Jurídica Trabalho e Desenvolvimento Humano, Campinas, EDIÇÃO ESPECIAL - DOSSIÊ COVID-19, p. 1-25, 2020. 
Revista Jurídica Trabalho e Desenvolvimento Humano Procuradoria Regional do Trabalho da 15ำ Região

de pandemia, tendo por premissa a vulnerabilidade do empregado, intensificada pelo momento de incertezas e medos relacionados à saúde, perda do emprego e fome.

\section{A vulnerabilidade do empregado em tempos de covid-19}

O histórico das sociedades atuais desafia discussões relacionadas à graduação das fragilidades reconhecidas previamente, não sendo apenas ligadas à afirmação de direitos, de sorte a englobar que vulnerabilidades podem estar presentes em uma única pessoa, agravando a sua condição ${ }^{1}$. O Estado Social, portanto, passa a se preocupar não só com as liberdades como também em implementar políticas que estejam relacionadas à redução de desigualdades fáticas, culturais e sociais, promovendo justiça social².

A palavra vulnerabilidade advém da junção dos termos em latim vulnerare (ferir) e velnerabilis (que causa lesão), fixando a propensão que alguém possa ter a ser ferido ou afetado $^{3}$. Na perspectiva jurídica, tem-se que a vulnerabilidade traduz uma qualidade provisória, contingente e particular de pessoas individualmente consideradas ou grupos sociais ${ }^{4}$.

No mundo do trabalho, a vulnerabilidade poderia ser vislumbrada em três prismas. 0 primeiro deles, aqui chamado de prisma psicológico, indica as características individuais relacionadas à conduta, enfrentamentos e capacidade de resposta frente às adversidades laborais, afinal todo ser humano, em certa medida, é vulnerável. Por outro lado, a vulnerabilidade também poderia ser enxergada no que tange às próprias características laborais, como o contrato em si, produtividade, exigências e organização do trabalho. 0 último prisma relaciona-se com a conjuntura política e socioeconômica do país, trazendo o paralelo

\footnotetext{
${ }^{1}$ ROSENVALD, Nelson. 0 direito civil em movimento: desafios contemporâneos. 2. ed., rev. e atual. Salvador: Juspodivm, 2018, p. 105-106.

${ }^{2}$ LÔBO, Paulo. Contratante vulnerável. In: NEVES, Thiago Ferreira Cardoso (coord). Direito e Justiça Social: por uma sociedade mais justa, livre e solidária: estudos em homenagem ao Professor Sylvio Capanema de Souza. São Paulo: Atlas, 2013, p. 160.

3 BARCHIFONTAINE, Christian de Paul de. Vulnerabilidade e Dignidade Humana. In: O Mundo da Saúde, São Paulo, ano 30, v. 30, n. 3, jul./set.2006, p. 435.

4 NEVES, Maria do Céu Patrão. Sentidos da vulnerabilidade: característica, condição, princípio. In: Revista brasileira de bioética, vol.2, n.2, 2006, p. 157-172, p. 160-161.
} 
Revista Jurídica Trabalho e Desenvolvimento Humano Procuradoria Regional do Trabalho da 15aㅡegião

entre a integração do trabalho e as expectativas de qualidade e proteção da vida sociofamiliar ${ }^{5}$.

O agravamento das fragilidades que são típicas do mundo laboral ocorre com a pandemia de COVID-19. Isso porque, a vulnerabilidade do trabalhador acaba por ultrapassar a barreira da relação jurídica em si, adentrando no sistema opressor das desigualdades sociais.

O medo de se tornar parte do contingente de desempregados no Brasil é uma realidade neste momento. Segundo a projeção do Instituto Brasileiro de Economia da Fundação Getúlio Vargas, do dia 24 de abril de 2020, o Brasil poderá encerrar este ano com uma taxa média de desemprego de $17,8 \%{ }^{6}$. Em tempos ditos como normais, o Brasil já tinha como marca distintiva empregos em que a rotatividade era alta e os salários baixos. Em 2019, a renda média de metade da população brasileira foi no valor de $\mathrm{R} \$ 850,00$ e houve aumento na desigualdade social. A alta concentração da renda per capita pode ser visualizada nos rendimentos de todos os trabalhos, uma vez que a renda da população $1 \%$ mais rica foi 33,7 vezes maior do que da metade da população mais pobre ${ }^{7}$.

Não se pode esquecer, também, que brasileiros enfrentam dificuldades para conseguir a liberação do Auxílio Emergencial disposto na Lei 13.892/2020, destinado àqueles trabalhadores que não possuem emprego formal ativo, no valor de $\mathrm{R} \$ 600,00$ durante três meses, em face da pandemia provocada pelo COVID-198. Nestes termos, aqueles que possuem empregos temem desemprego e aqueles que estão em situação de informalidade lutam para ter acesso a um direito garantido para a manutenção mínima da subsistência. Questiona-se, então, como seria possível achatar a curva de contaminação nestas condições, em que trabalhadores e empregados se encontram "na corda bamba". Ademais, a

\footnotetext{
${ }^{5}$ GARCÍA RUBIANO, M., et al. Diseño, construcción y validación de un instrumento para evaluar el riesgo psicolaboral en empresas colombianas. In: Diversitas - perspectivas en psicologia, vol. 4, n. 1, 2008, p. 39-40. ${ }^{6}$ PINHEIRO, Armando Castelar; MATOS, Silvia. Boletim Macro abril 2020. Fundação Getúlio Vargas - Instituto Brasileiro de Economia (IBRE). Disponível https://portalibre.fgv.br/data/files/BD/24/55/53/14CA1710199794F68904CBA8/BoletimMacrolbre_2004.pdf, Acesso em: 08 mai 2020.

${ }^{7}$ BRASIL. IBGE - Pnad Contínua. Disponível em: https://agenciadenoticias.ibge.gov.br/agencia-noticias/2012agencia-de-noticias/noticias/27596-nordeste-e-unica-regiao-com-aumento-na-concentracao-de-renda-em2019. Acesso em: 08 mai. 2020.

${ }^{8}$ BARBOSA, Marina. MPF pede esclarecimentos sobre concessão do benefício emergencial. Disponível em: https://www.correiobraziliense.com.br/app/noticia/economia/2020/05/05/internas economia,851483/mpfpede-esclarecimentos-sobre-a-concessao-do-beneficio-emergencial.shtml. Acesso em: 08 mai. 2020.
} 
Revista Jurídica Trabalho e Desenvolvimento Humano Procuradoria Regional do Trabalho da 15a Região

necessidade de alta produtividade gerada pelos interesses do empregador faz com que o empregado esteja numa posição de fragilidade intensa, afinal encontra-se inserido num ambiente organizacional em que a detenção dos meios de produção está nas mãos daquele que é mais forte na relação jurídica estabelecida ${ }^{9}$.

Infere-se a existência de vulnerabilidade negocial em face do desequilíbrio apresentado na relação jurídico trabalhista, haja vista que um indivíduo em particular se encontra numa posição de desvantagem em comparação ao outro sujeito daquela relação, que está em posição de maior poder negocial ${ }^{10}$. Ainda há a vulnerabilidade que é ínsita aos poderes do empregador no contrato de trabalho, poderes estes que não decorrem de mera hierarquia ou estado de submissão, mas sim, da sua posição de autoridade que leva ao comando, controle e gestão da atividade desenvolvida pelo empregado ${ }^{11}$.

A crise sanitária acelera, em verdade, um processo de crise no direito do trabalho que já estava anunciada, fruto do projeto neoliberal. Este se apresenta como novo, ensejando novas vulnerabilidades sociais, cultuando uma maior liberdade em prol do capital, ainda que ocasione precarização laboral ou aumento nas disparidades sociais ${ }^{12}$.

A dependência econômica do empregado em relação ao seu tomador ${ }^{13}$, latente no Brasil pela direção da exploração econômica fundada em práticas retrógradas para erradicação da pobreza, tem como premissa políticas de austeridade como única via para a recuperação da economia ${ }^{14}$. A crítica ao sistema de isolamento social em face do COVID-19,

\footnotetext{
${ }^{9}$ DORNELES, Leandro do Amaral D. de. Hipossuficiência e vulnerabilidade na teoria geral do direito do trabalho contemporânea. In: Revista LTr - Legislação do Trabalho, ano 77, n. 3, mar. 2013. p. 293-303. São Paulo: LTr, 2013, p. 295.

10 BATISTA, Neimar; AMORIM, Ana Rosa Tenório de. Vulnerabilidade no Direito privado: do conceito às aplicações. In: Revista Tuiuti: Ciência e Cultura, dossiê FACJUR, n. 57, c. 5. Curitiba, 2018, p. 82.

${ }^{11}$ RAMALHO, Maria do Rosário Palma. Tratado de Direito do Trabalho. Parte I - Dogmática Geral. 3. ed. rev. e atual. Coimbra: Almedina, 2012, p. 324.

12 COUTINHO, Aldacy Rachid. A autonomia privada: em busca da defesa dos direitos fundamentais dos trabalhadores. In: SARLET, Ingo Wolfgang (org.). Constituição, direitos fundamentais e direito privado. Porto Alegre: Livraria do Advogado, 2003, p. 166.

${ }^{13}$ ALONSO OLEA, Manuel. Introdução ao Direito do Trabalho. Porto Alegre: Livraria Sulina, 1969, p. 31-32.

${ }^{14}$ EMERIQUE, Lilian Balmant; DANTAS, Fernanda Lage. $O$ avanço da austeridade e o retrocesso na erradicação da pobreza. In: SILVA, Sayonara Grillo Coutinho Leonardo da; EMERIQUE, Lilian Balmant; BARISON, Thiago (org.). Reformas institucionais de austeridade, democracia e relações de trabalho. São Paulo: LTr, 2018, p. 37.
} 
Revista Jurídica Trabalho e Desenvolvimento Humano Procuradoria Regional do Trabalho da 15a Região

relacionada aos impactos econômicos e à suposta falta de benefícios em termos de saúde pública, ganha força nos noticiários brasileiros e demonstra exatamente esse fenômeno ${ }^{15}$.

A dependência do assalariado quanto à empresa é previa e faz parte da estrutura da sociedade capitalista, já que esta se funda na apropriação do trabalho alheio, com resultados pertencentes à pessoa diversa daquele obreiro ${ }^{16}$. A adversidade provocada pela pandemia do coronavírus exacerba ainda mais esta sujeição econômica e alienação do trabalhador, que resulta numa vulnerabilidade absurda pautada na sobrevivência e manutenção do vínculo ali estabelecido, como rota de fuga à massa de desempregados do Brasil.

\section{A autonomia privada e liberdade negocial individual no direito do trabalho}

O Direito enxerga a autonomia através do viés do direito fundamental à liberdade, fundamentando sua premissa na acepção de que sujeitos livres não são sujeitos de outrem ${ }^{17}$. Dessa forma, a autonomia vislumbra-se como uma ferramenta para a autorregulação da vida de um indivíduo por meio do exercício da sua liberdade, que necessita estar em consonância com os direitos de outros sujeitos, que também possuem idêntica cota de liberdade, além de promover igualdade e solidariedade ${ }^{18}$.

Nesse sentido, limitações ao direito fundamental à liberdade não podem ser tidas como negativas, uma vez que reforçam sua existência em sociedades livres e justas. Garantir liberdades básicas de forma igualitária é, portanto, garantir que seres humanos em posições desprivilegiadas, em face da vulnerabilidade, possam exercer suas autonomias, em perspectiva existencial e patrimonial ${ }^{19}$.

\footnotetext{
${ }^{15}$ FERRARI, Andrés; CUNHA, André Moreira. A pandemia de Covid-19 e o isolamento social: saúde versus economia. Disponível em: https://www.ufrgs.br/coronavirus/base/artigo-a-pandemia-de-covid-19-e-oisolamento-social-saude-versus-economia. Acesso em: 08 mai. 2020.

${ }^{16}$ MARX, Karl. Manuscritos Econômico-Filosóficos. Lisboa: Edições 70, 1964, p. 159-160.

${ }^{17}$ MIRANDA, Pontes de. Democracia, liberdade e igualdade: os três caminhos. 2. ed. São Paulo: Saraiva, 1979, p. 243.

18 SARMENTO, Daniel. Os princípios constitucionais da liberdade e da autonomia privada. In: LEITE, George Salomão (org.). Dos princípios constitucionais: considerações em torno das normas principiológicas da Constituição. São Paulo: Malheiros, 2003, p. 308.

${ }^{19}$ RAWLS, John. Justiça e democracia. São Paulo: Martins Fontes, 2002, p.144.
} 
Revista Jurídica Trabalho e Desenvolvimento Humano Procuradoria Regional do Trabalho da 15ำ Região

A perquirição por igualdade não significa que há uma posição superior deste direito fundamental diante da necessidade de tratamento desigual, bem como não se exclui a necessidade argumentativa relativa ao tratamento diferenciado, quando a abordagem desigual se faz necessária ${ }^{20}$. O desigualar necessita de razões satisfatórias e plausíveis para diferenciação, consistindo num caminho realizado pelo sistema jurídico acerca do ônus valorativo acerca deste tratamento desigual ${ }^{21}$.

Nestes termos, a autonomia privada não é expressão de uma mera licitude ou faculdade, sendo a "manifestación de poder y precisamente del poder de crear, dentro de los limites establecidos por la ley, normas jurídicas"22. Fala-se em autonomia privada, e não mais em autonomia da vontade, pois a vontade não é a fonte dos efeitos jurídicos, que ficam limitados à atuação do Estado em rechaçar a vontade, por meio do estabelecimento de um limite negativo, ou concordar com a vontade manifestada, o que seria tido como um limite positivo ${ }^{23}$.

A densidade legislativa se revela por meio da pluralidade de negócios jurídicos possíveis, de sorte que pode o Estado regular mais ou menos o exercício da autonomia privada, deixando um maior ou menor poder para atuação dos particulares na liberdade de criação das suas próprias normas jurídicas ${ }^{24}$.

Infere-se deste raciocínio que a autonomia é uma decorrência da atuação da liberdade individual, já que solidifica que o ser humano pode escolher aquilo que melhor the atende e que lhe garante bem estar na realização de negócios jurídicos ${ }^{25}$. Não reflete, contudo, uma liberdade negocial ilimitada, uma vez que o Estado possui a obrigação de fiscalizar este poder decorrente da autonomia privada.

\footnotetext{
${ }^{20}$ LUHMANN, Niklas. Los derechos fundamentales como institución: aportación a la sociología política. Mexico: Universidad Iberoamericana, 2010, p. 277.

${ }^{21}$ ALEXY, Robert. Teoria dos direitos fundamentais. Trad. Virgílio Afonso da Silva. São Paulo: Malheiros, 2008, p. 412-413.

${ }^{22}$ FERRI, Luigi. La autonomía privada. Trad. e notas de Luis Sancho Mendizábal. Granada: Comares, 2001, p. 7.

${ }^{23}$ PRATA, Ana. A tutela constitucional da autonomia privada. Lisboa: Almedina, 1982, p. 42-43.

${ }^{24}$ PENTEADO, Luciano de Camargo. Autonomia Privada E Negócios Jurídicos - Breves Notas. In: PUSCHEL, Flávia Portella. (Org.). Organização das relações privadas. São Paulo: Quartier Latin, 2007, v., p. 293-307, p. 304.

${ }_{25}$ MILL, John Stuart. Ensayo sobre la libertad. Trad. María Ángeles Lavilla Navarro. Madrid: Miestas Ediciones, 2006, p. 96-98.
}

WYZYKOWSKI, Adriana Brasil Vieira. Coronavírus e a farsa da liberdade negocial nos acordos individuais entre empregados e empregadores. Revista Jurídica Trabalho e Desenvolvimento Humano, Campinas, EDIÇÃO ESPECIAL - DOSSIÊ COVID-19, p. 1-25, 2020. 
Revista Jurídica Trabalho e Desenvolvimento Humano Procuradoria Regional do Trabalho da 15a Região

Faz-se necessário demarcar limites ou conformações à autonomia privada para que se possa obter uma conciliação e equilíbrio entre liberdade e igualdade, consolidando novos paradigmas com base nos valores constitucionais atuais. Equilibram-se, portanto, os interesses individuais com interesses individuais de outros seres humanos ${ }^{26}$, tornando-se a autonomia privada coerente com a lei, ordem pública e bons costumes, que são vistos como elementos de conformação do poder de autorregulação das relações jurídicas privadas ${ }^{27}$.

No Direito do Trabalho, a autonomia privada atua de forma diversa, a depender da esfera individual ou coletiva estabelecida. Isso se dá pois, nas relações individuais, em que há a presença do empregado, notadamente marcada pela vulnerabilidade, o espaço para a liberdade negocial é ínfimo, quiçá inexistente. A marca da subordinação e dependência do empregado, decorrentes do sistema capitalista e do liberalismo econômico, pressupôs, num primeiro momento, a existência de igualdade para fins de exploração da classe trabalhadora ${ }^{28}$. A necessidade de proteção levou à intervenção estatal e ao estabelecimento de novos parâmetros para a regulação do processo econômico, controlando a exploração do trabalho humano por aqueles que detinham o capital.

A relação subordinada entre empregado e empregador fundamenta-se no contrato de trabalho, sustentado, pois, pela autonomia privada. No entanto, este contrato, para a maioria dos empregados, é uma necessidade e não um ato de liberdade, designando apenas a nomeação de qual empregador este obreiro será subordinado ${ }^{29}$. Nota-se, portanto, não ser possível vislumbrar igualdade formal entre estes sujeitos, afinal o trabalho é, simultaneamente, unidade fundante do ser humano e meio de dominação dele, sincronicamente sujeito e objeto do contrato de emprego ${ }^{30}$.

\footnotetext{
${ }^{26}$ BORGES, Roxana Cardoso Brasileiro. Disponibilidade dos direitos da personalidade e autonomia privada. 2 ed. São Paulo: Saraiva, 2007, p.56.

${ }^{27}$ ALPA, Guido; BESSONE, Mario; ROPPO, Enzo. Rischo contrattuale e autonomia privata. Napoli: JOVENE EDITORE NAPOLI, 1982, p. 42.

${ }^{28}$ HUECK, Alfred; NIPPERDEY, H.C. Compendio de derecho del trabajo. Trad. PIÑERO, Miguel Rodriguez Piñero e Luis Enrique De La Villa. Madrid: Editorial Revista de Derecho Privado, 1963, p. 27.

${ }^{29}$ SUPIOT, Alain. Crítica do Direito do Trabalho. Trad. Antônio Monteiro Fernandes. Lisboa: Fundação Calouste Gulbenkian, 2016, p. 155.

${ }^{30}$ SUPIOT, Alain. Crítica do Direito do Trabalho. Trad. Antônio Monteiro Fernandes. Lisboa: Fundação Calouste Gulbenkian, 2016, p. 163.
} empregadores. Revista Jurídica Trabalho e Desenvolvimento Humano, Campinas, EDIÇÃO ESPECIAL - DOSSIÊ COVID-19, p. 1-25, 2020. 
Revista Jurídica Trabalho e Desenvolvimento Humano Procuradoria Regional do Trabalho da 15a Região

Indispensável na conjuntura do mundo do trabalho, pois, o princípio da proteção, uma vez que a relação jurídica trabalhista, enquanto relação de poder, necessita de instrumentos que visem atenuar a natural vulnerabilidade do empregado. Assim, o tratamento jurídico dado numa relação empregatícia nunca poderia ser igual ao tratamento existente nas relações cíveis padrão, pautadas numa presunção de igualdade ${ }^{31}$. O Direito, visualizando as disparidades econômicas, sociais e contratuais dos sujeitos contratantes, precisou criar mecanismos protetores, mediadores dos interesses dos empregados e empregadores, como garantia de uma igualdade real que alveja a liberdade contratual plena ${ }^{32}$.

Por isso, em âmbito individual, a liberdade negocial trabalhista sempre foi tida como ínfima, até mesmo pela rede de proteção criada neste ramo do Direito por meio do intervencionismo estatal e a atuação dos sindicatos na negociação coletiva, expressando a chamada autonomia privada coletiva ${ }^{33}$.

A autonomia privada coletiva é reconhecida pelo Estado diante da manifestação de interesses destoantes de grupos sociais organizados, como um sistema de regulação e normatização fruto da autonomia destes grupos no mundo do trabalho ${ }^{34}$. 0 interesse do grupo obreiro é desempenhado pelo sindicato, que atua na satisfação de um interesse comum, coletivo, em prol de melhorias para a categoria em questão ${ }^{35}$.

O exercício desta liberdade negocial coletiva consiste num recurso efetivo para promover solução de conflitos laborais, reestabelecendo a paz nestas relações, além de promover a regulação das relações de trabalho. Divergências são transformadas em confluências, com o objetivo precípuo de melhorias nas condições sociais e de trabalho ${ }^{36}$.

\footnotetext{
${ }^{31}$ SILVA, Luiz de Pinho Pedreira da. Principiologia do Direito do Trabalho. 2 ed. São Paulo: LTr, 1999, p. 24.

${ }^{32}$ COUTINHO, Aldacy Rachid. Autonomia privada na perspectiva do novo código civil. In: DALLEGRAVE NETO, José Affonso; GUNTHER, Luiz Eduardo (coord.). O impacto do novo Código Civil no Direito do Trabalho. São Paulo: LTr, 2003, p. 78.

33 PALOMEQUE, Manuel Carlos. Direito do trabalho e ideologia. Trad. Antônio Moreira. Coimbra: Almedina, 2001, p. 16.

${ }^{34}$ GIUGNI, Gino. Introducción al estúdio de la autonomia colectiva. Trad. y estudio preliminar de José Luis Monereo Pérez e José Antônio Fernández Avilés. Granada: Editorial Comares, 2004, s/p.

35 GAROFALI, Mario Giovanni. Interessi collettivi e comportamento antisindacale dell'imprenditore. Napoli: Editore Jovene Napoli, 1979, p.142-143.

${ }^{36}$ BUEN L., Néstor De. Derecho del Trabajo. Tomo Primero. Naucalpan de Juaréz: Editorial Porrúa, 1974, p. 66.
} 
Revista Jurídica Trabalho e Desenvolvimento Humano Procuradoria Regional do Trabalho da 15a Região

A complexidade da teia de proteção do empregado perpassa, assim, pela combinação entre o plano estatal, o plano coletivo e o plano individual. A autonomia privada coletiva diminui as assimetrias e devolve ao empregado sua condição de sujeito livre, dando-lhe, no plano coletivo, a autonomia de que ele é desapossado em âmbito individual ${ }^{37}$.

A essência do Direito do Trabalho, em resumo, se mostra por meio da proteção ao sujeito vulnerável da relação jurídico trabalhista, de sorte que a liberdade negocial individual cede espaço à atuação estatal e à atuação coletiva para conter os ímpetos da classe empresária diante da fragilidade e subordinação jurídica apresentadas pelos obreiros.

Frisa-se, no entanto, que o legislador estatal, marcado por ideais flexibilizatórias, estabeleceu, na Lei 13.467/17 - Reforma Trabalhista, a possibilidade de negociação individual pelos empregados chamados de hipersuficientes, conforme art. 444, parágrafo único da CLT. Estes empregados possuem poder negocial similar aos sindicatos, desde que possuam diploma de nível superior e percebam salário mensal igual ou superior a duas vezes o limite máximo dos benefícios do Regime Geral da Previdência Social.

A opção legislativa não levou em consideração a dependência econômica do empregado perante o empregador, a subordinação jurídica, o nível informacional laboral, dentre outras questões. Pela lei, "elevou-se" o status do trabalhador para atribuir simetria entre as partes e liberdade negocial, sendo que o fruto desta negociação prevalece, inclusive, sobre a negociação coletiva, descaracterizando o sistema de proteção advindo da autonomia privada coletiva previsto em sede constitucional ${ }^{38}$.

Neste momento, com a crise sanitária provocada pelo coronavírus, escancara-se esta predileção política pela negociação individual em sede laboral, que distorce o sistema protetivo trabalhista e enfraquece a atuação sindical, como se verá adiante.

\footnotetext{
${ }^{37}$ SUPIOT, Alain. Crítica do Direito do Trabalho. Trad. Antônio Monteiro Fernandes. Lisboa: Fundação Calouste Gulbenkian, 2016, p. 184.

38 MENDES, Marcus Menezes Barberino. Autonomia coletiva e a lei 13467/2017: apertem os cintos porque o garante do interesse público sumiu. Será? In: MAIOR, Jorge Luiz Souto; SEVERO, Valdete Souto. Resistência: aportes teóricos contra o retrocesso trabalhista. São Paulo: Expressão popular, 2017, p. 446.
}

WYZYKOWSKI, Adriana Brasil Vieira. Coronavírus e a farsa da liberdade negocial nos acordos individuais entre empregados e empregadores. Revista Jurídica Trabalho e Desenvolvimento Humano, Campinas, EDIÇÃO ESPECIAL - DOSSIÊ COVID-19, p. 1-25, 2020. 
Revista Jurídica Trabalho e Desenvolvimento Humano Procuradoria Regional do Trabalho da 15a Região

3. A farsa da liberdade negocial nos acordos individuais trabalhistas em tempos de covid-19

Incerteza, vírus, crise e colapso são palavras que passaram a fazer parte do cotidiano dos seres humanos desde que, ao final de 2019, a pandemia provocada pelo coronavírus assolou o mundo. No Brasil, não foi diferente, e medidas de enfrentamento diante do estado de calamidade pública reconhecido no Decreto Legislativo 6/2020 foram estabelecidas, afetando sensivelmente o mundo do trabalho. Não há, até a presente data, vacina ou medicamento, de sorte que medidas como isolamento, distanciamento e quarentena se mostram como as únicas eficazes para a diminuição da curva de contágio do vírus em questão, como já se relatou em outro momento nesta pesquisa.

O mundo do trabalho teve que experimentar, de forma abrupta, mudanças sensíveis, que impactam diretamente nos trabalhadores e que atingem o sistema de proteção social até então pensado. A Medida Provisória 927/2039, voltada à implementação de medidas de enfrentamento ao estado de calamidade pública, considerava que a catástrofe sanitária atual deveria ser encarada como hipótese de força maior, conforme art. 1ำ, parágrafo único. Remete-se ao art. 501 da CLT, que conceitua força maior "todo acontecimento inevitável, em relação à vontade do empregador, e para a realização do qual este não concorreu, direta ou indiretamente".

Embora o risco da atividade seja atribuído ao empregador, responsável pela atividade e organização do empreendimento no exercício da livre iniciativa (art. 2ำ da CLT), não se pode deixar de reconhecer a crise sanitária global e de proporções até então desconhecidas que está sendo vivenciada. O reconhecimento da hipótese de força maior pela MP 927/20, a priori, não ensejaria maiores discussões, estando justificada pela emergência sanitária provocada pelo COVID-19.

No entanto, o art. 2 da supracitada MP não poderia ser encarado da mesma forma. Indicava ele que seria possível celebração de acordo individual escrito entre empregado e empregador, a fim de garantir a permanência do vínculo empregatício, tendo este acordo

\footnotetext{
${ }^{39}$ A aludida Medida Provisória perdeu a validade no dia 19 de julho de 2020, ante a falta de consenso no Congresso Nacional acerca do conteúdo desta.
}

WYZYKOWSKI, Adriana Brasil Vieira. Coronavírus e a farsa da liberdade negocial nos acordos individuais entre empregados e empregadores. Revista Jurídica Trabalho e Desenvolvimento Humano, Campinas, EDIÇÃO ESPECIAL - DOSSIÊ COVID-19, p. 1-25, 2020. 
Revista Jurídica Trabalho e Desenvolvimento Humano Procuradoria Regional do Trabalho da 15a Região

preponderância aos demais instrumentos normativos, negociais e legais em face do estado de calamidade pública.

Alguns poderiam elucubrar a possibilidade de aplicação do art. 503 da CLT por conta de tais disposições, permitindo a redução geral dos salários dos empregados da empresa, proporcionalmente aos salários de cada um, não podendo ser superior a $25 \%$, respeitado o salário mínimo. A redação deste dispositivo da CLT, no entanto, é anterior ao texto constitucional vigente, que consagra o princípio da irredutibilidade salarial, ressalvado o disposto em acordo ou convenção coletiva, e a vedação ao retrocesso social.

Assim, não há como interpretar o dispositivo, ainda que no contexto da pandemia do COVID-19, sem levar em consideração a Constituição Federal de 1988, de sorte que a única interpretação possível é que o art. 503 da CLT foi parcialmente recepcionado pela constituição, já que a redução de salário somente será possível por negociação coletiva ${ }^{40}$. Pensar diferente seria ir de encontro ao texto constitucional, além de promover um terrorismo aos trabalhadores em relação à possibilidade de redução salarial sem a chancela do sindicato, conforme se abordará adiante.

Em privilégio a uma suposta liberdade negocial, a MP 927 ainda dispunha sobre a possibilidade de instalação do regime de teletrabalho por vontade unilateral do empregador, nos termos do art. 4․ Na mesma linha, poderia o empregador antecipar as férias e o gozo dos feriados do empregado, desde que realizasse a comunicação do período a ser gozado em 48 horas (art. 6 e 13) ou conceder férias coletivas, estando dispensadas as comunicações aos sindicatos e órgãos locais do Ministério da Economia (arts. 11 e 12).

0 art. 14, por sua vez, autorizava a interrupção das atividades pelo empregador e a constituição de regime de compensação de jornada por meio de banco de horas, desde que estabelecido por acordo coletivo ou individual, para compensação no prazo de até dezoito meses, contados do encerramento do estado de calamidade pública.

Além disso, em relação às medidas que consagravam acordos individuais escritos, 0 art. 26 permitia que os estabelecimentos de saúde, mesmo para atividades insalubres,

\footnotetext{
${ }^{40}$ No mesmo sentido, ver: MARTINEZ, Luciano. Curso de Direito do Trabalho. 9. ed. São Paulo: Saraiva, 2018, p. 753 e DELGADO, Maurício Godinho. Curso de Direito do Trabalho. 18. Ed. São Paulo: LTr, 2019, p. 497.
}

WYZYKOWSKI, Adriana Brasil Vieira. Coronavírus e a farsa da liberdade negocial nos acordos individuais entre empregados e empregadores. Revista Jurídica Trabalho e Desenvolvimento Humano, Campinas, EDIÇÃO ESPECIAL - DOSSIÊ COVID-19, p. 1-25, 2020. 
Revista Jurídica Trabalho e Desenvolvimento Humano Procuradoria Regional do Trabalho da 15a Região

pactuassem com seus empregados jornada de 12 horas por 36 horas de descanso, sendo possível prorrogação de jornada e escalas de horas suplementares entre a 13a e a 24a hora, garantido o repouso semanal remunerado.

O encanto pela negociação individual trabalhista, identicamente, está presente na Medida Provisória 936/20, convertida na Lei 14.020/20, que institui o Programa Emergencial de Manutenção do Emprego e da Renda durante o estado de calamidade pública. Suas principais medidas são o pagamento do benefício emergencial de preservação do emprego e da renda ${ }^{41}$, a redução proporcional de jornada de trabalho e salários e a suspensão temporária do contrato de trabalho (art. 3우).

Poderá o empregador acordar a redução proporcional da jornada de trabalho e salário dos seus empregados, por até 90 dias, desde que se preserve o valor do salário-hora do trabalhador, que se respeitem os percentuais de 25,50 ou $70 \%$, e seja pactuado acordo individual escrito, encaminhado ao empregado com antecedência de, no mínimo, dois dias corridos (art. 7).

De igual modo, o art. 8 o traz a possibilidade de suspensão temporária do contrato de trabalho, pelo prazo máximo de 60 dias, fracionado em até dois períodos de 30 dias. A suspensão também poderá ser pactuada por acordo individual escrito entre empregado e empregador, que precisará ser enviado com antecedência mínima de dois dias corridos.

De forma aparentemente diversa da enunciada pelos artigos citados anteriormente, 0 artigo 11 afirma que as medidas de redução de jornada com redução salarial e suspensão temporária do contrato de emprego poderão ser alvo de negociação coletiva, enquanto o art. 12 assevera que as mesmas medidas serão implementadas por meio de acordo individual ou

\footnotetext{
${ }^{41}$ Art. 60 0 valor do Benefício Emergencial de Preservação do Emprego e da Renda terá como base de cálculo o valor mensal do seguro-desemprego a que o empregado teria direito, nos termos do art. 5 da Lei no 7.998, de 1990, observadas as seguintes disposições:

I - na hipótese de redução de jornada de trabalho e de salário, será calculado aplicando-se sobre a base de cálculo o percentual da redução; e

II - na hipótese de suspensão temporária do contrato de trabalho, terá valor mensal:

a) equivalente a cem por cento do valor do seguro-desemprego a que o empregado teria direito, na hipótese prevista no caput do art. 8; ou

b) equivalente a setenta por cento do seguro-desemprego a que o empregado teria direito, na hipótese prevista no $\S 5$ ㅇ do art. 8‥

$[\ldots]$
}

WYZYKOWSKI, Adriana Brasil Vieira. Coronavírus e a farsa da liberdade negocial nos acordos individuais entre empregados e empregadores. Revista Jurídica Trabalho e Desenvolvimento Humano, Campinas, EDIÇÃO ESPECIAL - DOSSIÊ COVID-19, p. 1-25, 2020. 
Revista Jurídica Trabalho e Desenvolvimento Humano Procuradoria Regional do Trabalho da 15a Região

de negociação coletiva nas seguintes hipóteses, apenas: a) empregados com salário igual ou inferior a dois mil e noventa reais, na hipótese de o empregador ter auferido, no anocalendário de 2019, receita bruta superior a quatro milhões e oitocentos mil reais; b) empregados com salário igual ou inferior a três mil, cento e trinta e cinco reais, na hipótese de o empregador ter auferido, no ano calendário de 2019, receita bruta igual ou inferior a quatro milhões e oitocentos mil reais; c) empregados portadores de diploma de nível superior e que percebam salário mensal igual ou superior a duas vezes o limite máximo dos benefícios do Regime Geral de Previdência Social. Para aqueles empregados não enquadrados nesta regra, as disposições apenas podem ser estabelecidas por acordo ou convenção coletiva, salvo as seguintes situações: a) redução proporcional de jornada de trabalho e de salário de $25 \%$, conforme alínea "a" do inciso III do caput do art. 70 da aludida lei; b) quando ocorrer redução proporcional de jornada de trabalho e de salário ou suspensão temporária do contrato de trabalho quando do acordo não resultar diminuição do valor total recebido mensalmente pelo empregado.

Os dispositivos em comento solidificam ofensas a diversas normas constitucionais. Se não bastasse a notória violação aos preceitos que envolvem a necessidade de negociação coletiva para redução salarial e redução de jornada (art.7, incisos VI e XIII da CF/88), o art. 12 promove uma discriminação direta por conta de patamar salarial ou formação intelectual ao forjar uma autonomia negocial que enseja diferenciação protetiva ${ }^{42}$, desconsiderando as diversas vulnerabilidades existentes e pronunciadas na pandemia atual.

Assinala-se que, em sua composição plenária, nos autos da ADI $6363^{43}$, ajuizada pelo Partido Rede de Sustentabilidade, o Supremo Tribunal Federal decidiu, por maioria, pela cassação da liminar deferida anteriormente pelo Ministro Ricardo Lewandowski, sendo vencidos, além do relator, o Ministro Luiz Edson Fachin e a Ministra Rosa Weber. A decisão, embora não tenha sido proferida em cognição exauriente, girou em torno das discussões

\footnotetext{
42 WYZYKOWSKI, Adriana. Autonomia privada e vulnerabilidade do empregado: critérios para o exercício da liberdade negocial individual no Direito do Trabalho. Rio de Janeiro: Lumen Juris, 2019, p. 141.

43 BRASIL. Supremo Tribunal Federal. Ação Direita de Inconstitucionalidade no 6363/DF - Relator: Ministro Ricardo Lewandowski. Pesquisa de Jurisprudência. Decisão: 17 abr. 2020. Disponível em: http://portal.stf.jus.br/processos/detalhe.asp?incidente=5886604, Acesso em: 19 mai. 2020.
} 
Revista Jurídica Trabalho e Desenvolvimento Humano Procuradoria Regional do Trabalho da 15a Região

acerca da ofensa ao art. 7으, VI e XIII da CF/88 em face da regra da MP 936/2020, que autoriza redução da jornada de trabalho ou do salário por acordos individuais em razão da pandemia do coronavírus, independentemente da anuência dos sindicatos da categoria.

Em 6 de abril de 2020, o ministro Ricardo Lewandowski havia deferido parcialmente a medida cautelar para determinar que, após serem comunicados dos acordos individuais, os sindicatos pudessem se manifestar acerca da sua validade, afinal a redução salarial apenas poderia ocorrer mediante negociação coletiva (art. 7으, VI, CF/88). Nesta senda, para o Ministro Relator, não haveria espaço para que a legislação ordinária substituísse a participação sindical em acordos com essa finalidade, em respeito à autonomia privada coletiva, posição esta que não foi seguida pela maioria da composição do STF.

No entanto, segundo posição adotada pelo STF no RE 220.271, a decisão que rejeita a medida liminar em ADI não é dotada de eficácia vinculante, uma vez que o art. $11, \S 1$ o da Lei 9.858/99, dispõe que "a medida cautelar, dotada de eficácia contra todos, será concedida com efeito ex nunc, salvo se o Tribunal entender que deva conceder-Ihe eficácia retroativa". Defende-se, em breves linhas, que até que seja analisado o mérito da ADI 6363, é possível decisões advindas de outras instâncias trabalhistas com conteúdo contrário à decisão proferida pelo Supremo Tribunal Federal.

Mas por que adotar uma posição tão rígida e contrária, inclusive, a uma decisão (não vinculante) do STF, numa situação de caos e incertezas como a pandemia do COVID-19? Explica-se. O momento de crise sanitária, de doenças, inseguranças e mortes não pode servirse ao propósito neoliberal. A vulnerabilidade do trabalhador, em verdade, encontra-se muito mais agravada durante a pandemia, comprometendo sua autodeterminação e, consequentemente, sua liberdade negocial, tão discutível antes mesmo da crise sanitária.

A vulnerabilidade está presente em todo ser humano, o que faz com que, em certa medida, todo trabalhador experimente a sensação de fragilidade no desenrolar da sua relação empregatícia. Mesmo aquele que não tem consciência desta condição pode, a qualquer 
Revista Jurídica Trabalho e Desenvolvimento Humano Procuradoria Regional do Trabalho da 15a Região

momento, estar numa situação de dependência diante de organizações precárias, que não tem como objetivo a promoção da sua autodeterminação e liberdade verdadeira ${ }^{44}$.

A lógica capitalista, na atualidade e no enfrentamento ao COVID-19, busca promover a insegurança do trabalhador, num jogo de opressão contraditório aos interesses da vida, bem-estar e saúde destes ${ }^{45}$. Tal dialética, advinda do regime pós-toyotista, estimula que o empregado creia que tem autonomia, já que reage em tempo real aos comandos e sinais que são emitidos pelo empregador, por meio de uma disponibilidade que possibilita o controle dos seus $\operatorname{corpos}^{46}$. É a ideologia da autonomia programada, mas que, para quem está inserido no sistema, é vista como única condição, fazendo com que muitos trabalhadores acreditem que há um alinhamento entre as suas demandas e demandas do empregador.

O que se observa, em verdade, é a dissolução da proteção social do trabalho pela utilização de um discurso que valoriza o trabalho autônomo e a liberdade nas relações jurídico-laborais, artifício que corrobora com a ruína das resistências trabalhistas pela promoção de uma autonomia falsificada, que em nada permite a liberdade negocial individual proposta pelas normas em questão.

A exploração do trabalhador é enaltecida por meio de uma política neoliberal que estimula a liberdade sem medidas, numa autonomia que reflete uma pantomima, com o ardil da manipulação dos obreiros que, convencidos de que são livres, acabam por associar-se à preservação da exploração ${ }^{47}$. Perde-se a identificação e pertencimento a uma classe, minando a autonomia coletiva e alienando o trabalhador em favor do empregador.

Disposições acerca das medidas de enfrentamento do COVID-19 precisam ser discutidas e negociadas pela via sindical, sob pena de um enfraquecimento ainda maior dos sindicatos brasileiros. Ademais, sabe-se que sindicatos fragilizados colaboram para um

\footnotetext{
44 FERREIRA, António Casimiro. Sociedade da austeridade e direito do trabalho de exceção. Porto: Vida econômica, 2012, p. 134.

45 DUTRA, Renata Queiroz. Trabalho, regulação e cidadania: a dialética da regulação social do trabalho. São Paulo: LTr, 2018, p. 23.

${ }^{46}$ OITAVEN, Juliana Carreiro Corbal; CARELLI, Rodrigo de Lacerda; CASAGRANDE, Cássio Luís. Empresas de transporte, plataformas digitais e relação de emprego: um estudo do trabalho subordinado sob aplicativos. Brasília: Ministério Público do Trabalho, 2018, p. 30.

47 BOURDIEU, Pierre. La double vérité du travail. Actes de la recherche en sciences sociales, Paris, v. 114, p. 8990, set. 1996, p. 89. Disponível em: https://www.persee.fr/doc/arss 0335-5322 1996 num 11413197 , Acesso: em 17 abr. 2019.
}

WYZYKOWSKI, Adriana Brasil Vieira. Coronavírus e a farsa da liberdade negocial nos acordos individuais entre empregados e empregadores. Revista Jurídica Trabalho e Desenvolvimento Humano, Campinas, EDIÇÃO ESPECIAL - DOSSIÊ COVID-19, p. 1-25, 2020. 
Revista Jurídica Trabalho e Desenvolvimento Humano Procuradoria Regional do Trabalho da 15a Região

modelo de precarização social do trabalho, que acaba por resultar numa luta selvagem pela manutenção no emprego, com possíveis renúncias a direitos trabalhistas.

A garantia dos instrumentos coletivos prevista no ordenamento constitucional garante seu status normativo, de sorte que suas cláusulas são verdadeiras normas de caráter geral, que servem de base para os contratos individuais de trabalho ${ }^{48}$. Não há como negar este papel aos sindicatos, responsáveis pela defesa dos interesses da categoria. Não obstante, observase que os dispositivos das Medidas Provisórias supracitadas violam o art. 7ํ, XXVI da CF/88, que impõe o reconhecimento das convenções e acordos coletivos de trabalho. No mesmo sentido, Guilherme Ludwig $^{49}$ afirma que não há norma constitucional que autorize a desconsideração temporária e emergencial de outras normas constitucionais, salvo em hipóteses delimitadas de estado de defesa e estado de sítio.

Também não se pode esquecer que o modelo adotado possui sério problema de constitucionalidade quando traz a possibilidade de redução salarial, redução de jornada com redução de salário e suspensão do contrato de emprego pela via negocial individual. Ora, o art. 7ํ, $\mathrm{VI}$ da CF/88 determina expressamente a necessidade de participação efetiva dos sindicatos nas reduções salariais, sendo este entendimento, inclusive, reconhecido em sede de jurisprudência do Tribunal Superior do Trabalho ${ }^{50}$.

48 MELGAR, Alfredo Montoya; MORENO, Jesus Maria Galiano; NAVARRO, Antônio Vicente; SAEZ, Ignacio Durendez; SALMERON, Bartolome Rios. La Obra cientifica de Manuel Alonso Olea: en sus XXV años de Catedrático de Derecho del Trabajo. Murcia: Editum, 1983, p. 95-96.

${ }^{49}$ LUDWIG, Guilherme Guimarães. Medidas trabalhistas emergenciais no estado de calamidade pública: uma análise constitucional e sistemática das medidas provisórias 927, 936, 944, 945 e 946/2020. In: Academia Brasileira de Direito do Trabalho. 2020. Disponível em: http://www.andt.org.br/f/MEDIDAS\%20TRABALHISTAS\%20EMERGENCIAIS\%20NO\%20ESTADO\%20DE\%20CALA MIDADE\%20PU\%CC\%81BLICA\%20+.pdf. Acesso em 19 mai. 2020.

50 RECURSO DE EMBARGOS. RECURSO DE REVISTA CONHECIDO E DESPROVIDO. BORLEM. AUMENTO REAL CONVERTIDO EM ANTECIPAÇÃO SALARIAL. REDUÇÃO SALARIAL. AUSÊNCIA DE PARTICIPAÇÃO DA ENTIDADE SINDICAL. O inciso VI do artigo 7.ㅇ da Constituição Federal estabelece que só pode haver redução salarial mediante convenção ou acordo coletivo de trabalho. Logo, a conversão do aumento real concedido pela Reclamada em antecipação salarial tão-somente seria possível mediante a participação do sindicato de classe dos trabalhadores. Assim, é inviável o conhecimento do Recurso de Embargos que objetiva desconstituir a decisão embargada que se encontra moldada à jurisprudência iterativa, notória e atual da Seção Especializada em Dissídios Individuais desta Corte, in casu, a aplicação do entendimento consubstanciado na Orientação Jurisprudencial de n. 325 da SBDI-1. Embargos não conhecidos. (BRASIL. Tribunal Superior do Trabalho. E-RR523589-75.1998.5.02.5555. Relatora: Min. Maria de Assis Calsing. Pesquisa de Jurisprudência. Decisão: 10 mar. 2008. Disponível em: https://jurisprudencia.tst.jus.br/. Acesso em: 19 mai. 2020.

WYZYKOWSKI, Adriana Brasil Vieira. Coronavírus e a farsa da liberdade negocial nos acordos individuais entre empregados e empregadores. Revista Jurídica Trabalho e Desenvolvimento Humano, Campinas, EDIÇÃO ESPECIAL - DOSSIÊ COVID-19, p. 1-25, 2020. 
Revista Jurídica Trabalho e Desenvolvimento Humano Procuradoria Regional do Trabalho da 15a Região

Tal determinação constitucional é de suma importância, uma vez que o Direito do Trabalho visa reduzir a coação econômica, que acaba por viciar a vontade daqueles que são mais fracos em relação aos economicamente e contratualmente mais fortes ${ }^{51}$. 0 empregado, diante de uma situação concreta pautada numa desigualdade fática e jurídica, não teria como negociar individualmente questões como redução do salário ou redução da jornada com redução proporcional do salário, sob pena da inversão da lógica protetora do Direito do Trabalho, afinal "a liberdade na miséria nada mais poderia significar do que uma ficção jurídica" ${ }^{52}$. Não adianta falar num paternalismo supressor da liberdade individual se não há igualdade na relação jurídica estabelecida.

É salutar relembrar, neste momento, que nem mesmo igualdade econômica existe entre os valores do benefício emergencial e salário do empregado que foi reduzido, em face do cálculo ser feito com base no seguro-desemprego (art. 6 da Lei 14.020/20), além de ter o benefício emergencial natureza jurídica indenizatória. Os prejuízos recaem, mais uma vez, do lado mais fraco da relação empregatícia, o que legitima a atuação sindical.

A importância da negociação pela via sindical mostra-se imprescindível, como um alinhamento da maximização dos interesses da categoria e ressignificação do sindicato na atualidade, afinal este se encontra, pelo menos teoricamente, numa posição de paridade perante o empregador. Não se pode desprezar o parâmetro constitucional dos direitos trabalhistas, nos quais se encontram a irredutibilidade salarial, participação e reconhecimento da importância dos sindicatos, sob pena de retrocesso social. A crise sanitária provocada pelo COVID-19 não pode servir como subterfúgio para regredir ao passado, promovendo a perda do sentido constitucional dos direitos sociais.

A proibição de retrocesso impede, portanto, que aquele que possui o poder normativo adote norma que reduza ou derrogue as conquistas dos direitos sociais, econômicos e

\footnotetext{
51 CATHARINO, José Martins. Compêndio de direito do trabalho. vol. 1. 2. ed. rev., atual. e aum. São Paulo: Saraiva, 1981, p. 201-202.

52 DONATO, Messias Pereira. O movimento sindical operário no regime capitalista. Belo Horizonte: Revista Brasileira de Estudos Políticos, 1959, p. 28.
} 
Revista Jurídica Trabalho e Desenvolvimento Humano Procuradoria Regional do Trabalho da 15a Região

culturais vigentes $^{53}$. A liberdade negocial necessita, assim, ser orientada pela pluralidade de valores que conformam a ordem constitucional, refletindo o princípio da solidariedade. Por isso, esta pesquisa adota a necessidade de uma postura colaborativa e positiva da liberdade negocial no Direito do Trabalho, de sorte a resguardar a atuação sindical nos acordos relacionados à redução de salário ou jornada dos empregados por conta da pandemia do coronavírus.

Não é possível o descumprimento sistemático do núcleo essencial constitucional, quer seja, os direitos fundamentais. A Constituição mostra sua força normativa ao traçar diretrizes, constituir direitos fundamentais, dirigindo e mostrando referências para a atuação dos sujeitos sociais ${ }^{54}$. Nas relações de poder, a proteção daqueles que estão em posição de vulnerabilidade é vital, mesmo que esse poder não seja apenas jurídico ${ }^{55}$. Justifica-se, assim, a atuação do princípio da igualdade e solidariedade, alavancando-se o avançar civilizatório com a participação dos sindicatos, tendo por base vulnerabilidade ainda mais acentuada do empregado em tempos de COVID-19. Barreiras e retrocessos na atuação sindical apenas conduzem ao agravamento da crise vivenciada pelo artifício da dissolução da proteção social do trabalho, além de desnudar que violações constitucionais são toleradas no ordenamento jurídico brasileiro.

\section{Considerações finais}

I - O grave momento de crise sanitária por conta da propagação do coronavírus fez com que medidas de enfrentamento fossem estabelecidas no âmbito da regulação do trabalho, trazendo discussões acerca das disposições estabelecidas na Medidas Provisórias

\footnotetext{
${ }^{53}$ COURTIS, Christian. La prohibición de regresividad em matéria de derechos sociales: apuntes introductorios. In: COURTIS, Christian (coord.). Ni un paso atrás: La prohibición de regresividad em matéria de derechos sociales. Buenos Aires: Del Puerto, 2006, p. 17-18.

${ }^{54}$ STRECK, Lenio Luiz. Verdade \& Consenso: Constituição, Hermenêutica e teorias discursivas - Da possibilidade à necessidade de respostas corretas no Direito. Rio de Janeiro: Lúmen Juris Editora, 2008, p. 114- 115.

${ }^{55}$ ANDRADE, José Carlos Vieira de. Os Direitos Fundamentais na Constituição Portuguesa de 1976. 5. ed. Coimbra: Almedina, 2012, p. 245.
} 
927 e 936, esta última convertida na Lei 14.020/20, que promovem, em síntese, liberdade negocial individual entre empregado e empregador, justificada pela pandemia.

II - No entanto, não se levou em consideração que este momento enseja um agravamento das vulnerabilidades, que já são típicas do mundo do trabalho. A relação jurídica trabalhista, por si só, já coloca o empregado numa posição de debilidade frente ao empregador, por não ser o obreiro detentor dos meios de produção e estar sujeito aos poderes que o empregador possui. A COVID-19 exacerba estas vulnerabilidades, adentrando no campo da opressão pelas desigualdades sociais e desemprego latente.

III - A autonomia funciona como uma ferramenta para a autorregulação da vida dos seres humanos pelo exercício do direito fundamental à liberdade. Não pode, contudo, estar em dissonância do direito à igualdade, sob pena de promover perpetuação das vulnerabilidades. No Direito do Trabalho, a rede de proteção trabalhista faz com que a autonomia privada, enquanto poder de criar normas jurídicas dentro dos limites estabelecidos pelo ordenamento, seja ínfima em esfera individual, ressalvado o disposto no art. 444, par. único da CLT, encontrando terreno mais fértil em sede coletiva.

IV - Negociações individuais, sempre vistas com ressalvas por conta do desequilíbrio marcante da relação de emprego, foram privilegiadas com as normas emergenciais trabalhistas, sob a justificativa de que o estado de calamidade pública causado pelo COVID-19 exige medidas rápidas e simplificadas, seja para a manutenção dos empregos, seja para viabilidade das atividades empresariais.

V - Não obstante, as normas jurídicas em questão desconsideram a necessidade de negociação coletiva para redução de jornada e redução salarial, conforme art. 7으, VI da CF/88, enfraquecendo o sindicato e, consequentemente, a autonomia privada coletiva.

VI - Além da notória inconstitucionalidade dos trechos das normas emergenciais trabalhistas que autorizam os acordos individuais, entende-se que a valorização da negociação individual busca promover ideais neoliberais da dialética capitalista, com domínio por parte do empregador das decisões e demandas dos empregados, numa forma de autonomia programada.

WYZYKOWSKI, Adriana Brasil Vieira. Coronavírus e a farsa da liberdade negocial nos acordos individuais entre empregados e empregadores. Revista Jurídica Trabalho e Desenvolvimento Humano, Campinas, EDIÇÃO ESPECIAL - DOSSIÊ COVID-19, p. 1-25, 2020. 
Revista Jurídica Trabalho e Desenvolvimento Humano Procuradoria Regional do Trabalho da 15a Região

VII - Essa autonomia falsificada, portanto, leva à dissolução da proteção social do trabalho e arruína as resistências trabalhistas ao incentivar uma liberdade sem medidas, que desconsidera o estado de vulnerabilidade dos empregados. Mina-se a autonomia coletiva com as Medidas Provisórias supracitadas, atrofiando a atuação sindical, garantida constitucionalmente. Não se pode usar a crise sanitária a serviço da lógica da exploração do trabalhador e para promover ofensas a direitos constitucionalmente garantidos. Conclui-se, portanto, que medidas para enfrentamento da COVID-19 precisam da chancela do sindicato, sob pena da ruína da rede de proteção social constitucional trabalhista.

\section{Referências}

ALEXY, Robert. Teoria dos direitos fundamentais. Trad. Virgílio Afonso da Silva. São Paulo: Malheiros, 2008.

ALONSO OLEA, Manuel. Introdução ao Direito do Trabalho. Porto Alegre: Livraria Sulina, 1969.

ALPA, Guido; BESSONE, Mario; ROPPO, Enzo. Rischo contrattuale e autonomia privata. Napoli: JOVENE EDITORE NAPOLI, 1982.

ANDRADE, José Carlos Vieira de. Os Direitos Fundamentais na Constituição Portuguesa de 1976. 5. ed. Coimbra: Almedina, 2012.

BARBOSA, Marina. MPF pede esclarecimentos sobre concessão do benefício emergencial. Disponível em:

https://www.correiobraziliense.com.br/app/noticia/economia/2020/05/05/internas econo mia,851483/mpf-pede-esclarecimentos-sobre-a-concessao-do-beneficio-emergencial.shtml. Acesso em: 08 mai. 2020.

BARCHIFONTAINE, Christian de Paul de. Vulnerabilidade e Dignidade Humana. In: O Mundo da Saúde, São Paulo, ano 30, v. 30, n. 3, jul./set.2006, p. 434-440.

BATISTA, Neimar; AMORIM, Ana Rosa Tenório de. Vulnerabilidade no Direito privado: do conceito às aplicações. In: Revista Tuiuti: Ciência e Cultura, dossiê FACJUR, n. 57, c. 5. Curitiba, 2018.

BORGES, Roxana Cardoso Brasileiro. Disponibilidade dos direitos da personalidade e autonomia privada. 2 ed. São Paulo: Saraiva, 2007. 
Revista Jurídica Trabalho e Desenvolvimento Humano Procuradoria Regional do Trabalho da 15a Região

BOURDIEU, Pierre. La double vérité du travail. Actes de la recherche en sciences sociales, Paris, v. 114, p. 89-90, set. 1996, p. 89. Disponível em:

https://www.persee.fr/doc/arss 0335-5322 1996 num 1141 3197. Acesso em: 17 abr. 2020.

BRASIL. IBGE - Pnad Contínua. Disponível em: https://agenciadenoticias.ibge.gov.br/agencianoticias/2012-agencia-de-noticias/noticias/27596-nordeste-e-unica-regiao-com-aumentona-concentracao-de-renda-em-2019. Acesso em: 08 mai. 2020.

BRASIL. Supremo Tribunal Federal. Ação Direita de Inconstitucionalidade no 6363/DF Relator: Ministro Ricardo Lewandowski. Pesquisa de Jurisprudência. Decisão: 17 abr. 2020. Disponível em: http://portal.stf.jus.br/processos/detalhe.asp?incidente $=5886604$, Acesso em: 19 mai. 2020.

BRASIL. Tribunal Superior do Trabalho. E-RR-523589-75.1998.5.02.5555. Min. Relatora: Maria de Assis Calsing. Pesquisa de Jurisprudência. Decisão: 10/03/2008. Disponível em: https://jurisprudencia.tst.jus.br/. Acesso em 19 mai. 2020.

BUEN L., Néstor De. Derecho del Trabajo. Tomo Primero. Naucalpan de Juaréz: Editorial Porrúa, 1974.

CATHARINO, José Martins. Compêndio de direito do trabalho. vol. 1. 2. ed. rev., atual. e aum. São Paulo: Saraiva, 1981.

COURTIS, Christian. La prohibición de regresividad em matéria de derechos sociales: apuntes introductorios. In: COURTIS, Christian (coord.). Ni un paso atrás: La prohibición de regresividad em matéria de derechos sociales. Buenos Aires: Del Puerto, 2006.

COUTINHO, Aldacy Rachid. A autonomia privada: em busca da defesa dos direitos fundamentais dos trabalhadores. In: SARLET, Ingo Wolfgang (org.). Constituição, direitos fundamentais e direito privado. Porto Alegre: Livraria do Advogado, 2003.

Autonomia privada na perspectiva do novo código civil. In: DALLEGRAVE NETO, José Affonso; GUNTHER, Luiz Eduardo (coord.). O impacto do novo Código Civil no Direito do Trabalho. São Paulo: LTr, 2003.

DELGADO, Maurício Godinho. Curso de Direito do Trabalho. 18. Ed. São Paulo: LTr, 2019.

DONATO, Messias Pereira. O movimento sindical operário no regime capitalista. Belo Horizonte: Revista Brasileira de Estudos Políticos, 1959. 
Revista Jurídica Trabalho e Desenvolvimento Humano Procuradoria Regional do Trabalho da 15ำ Região

DORNELES, Leandro do Amaral D. de. Hipossuficiência e vulnerabilidade na teoria geral do direito do trabalho contemporânea. In: Revista LTr - Legislação do Trabalho, ano 77, n. 3, mar. 2013. p. 293-303. São Paulo: LTr, 2013.

DUTRA, Renata Queiroz. Trabalho, regulação e cidadania: a dialética da regulação social do trabalho. São Paulo: LTr, 2018.

EMERIQUE, Lilian Balmant; DANTAS, Fernanda Lage. O avanço da austeridade e o retrocesso na erradicação da pobreza. In: SILVA, Sayonara Grillo Coutinho Leonardo da; EMERIQUE, Lilian Balmant; BARISON, Thiago (org.). Reformas institucionais de austeridade, democracia e relações de trabalho. São Paulo: LTr, 2018.

FERRARI, Andrés; CUNHA, André Moreira. A pandemia de Covid-19 e o isolamento social: saúde versus economia. Disponível em: https://www.ufrgs.br/coronavirus/base/artigo-apandemia-de-covid-19-e-o-isolamento-social-saude-versus-economia. Acesso em: 08 mai. 2020.

FERREIRA, António Casimiro. Sociedade da austeridade e direito do trabalho de exceção. Porto: Vida econômica, 2012.

FERRI, Luigi. La autonomía privada. Trad. e notas de Luis Sancho Mendizábal. Granada: Comares, 2001.

GARCÍA RUBIANO, M., et al. Diseño, construcción y validación de un instrumento para evaluar el riesgo psicolaboral en empresas colombianas. In: Diversitas - perspectivas en psicologia, vol. 4, n. 1, 2008, p. 37-51.

GAROFALI, Mario Giovanni. Interessi collettivi e comportamento antisindacale dell’imprenditore. Napoli: Editore Jovene Napoli, 1979.

GIUGNI, Gino. Introducción al estúdio de la autonomia colectiva. Trad. y estúdio preliminar de José Luis Monereo Pérez e José Antônio Fernández Avilés. Granada: Editorial Comares, 2004.

HUECK, Alfred; NIPPERDEY, H.C. Compendio de derecho del trabajo. Trad. PIÑERO, Miguel Rodriguez Piñero e Luis Enrique De La Villa. Madrid: Editorial Revista de Derecho Privado, 1963.

LÔBO, Paulo. Contratante vulnerável. In: NEVES, Thiago Ferreira Cardoso (coord). Direito e Justiça Social: por uma sociedade mais justa, livre e solidária: estudos em homenagem ao Professor Sylvio Capanema de Souza. São Paulo: Atlas, 2013. 
Revista Jurídica Trabalho e Desenvolvimento Humano Procuradoria Regional do Trabalho da 15a Região

LUDWIG, Guilherme Guimarães. Medidas trabalhistas emergenciais no estado de calamidade pública: uma análise constitucional e sistemática das medidas provisórias 927, 936, 944, 945 e 946/2020. In: Academia Brasileira de Direito do Trabalho. 2020. Disponível em: http://www.andt.org.br/f/MEDIDAS\%20TRABALHISTAS\%20EMERGENCIAIS\%20NO\%20ESTAD O\%20DE\%20CALAMIDADE\%20PU\%CC\%81BLICA\%20+.pdf. Acesso em: 19 mai. 2020.

LUHMANN, Niklas. Los derechos fundamentales como institución: aportación a la sociología política. Mexico: Universidad Iberoamericana, 2010.

MARTINEZ, Luciano. Curso de Direito do Trabalho. 9. ed. São Paulo: Saraiva, 2018.

MARX, Karl. Manuscritos Econômico-Filosóficos. Lisboa: Edições 70, 1964.

MELGAR, Alfredo Montoya; MORENO, Jesus Maria Galiano; NAVARRO, Antônio Vicente; SAEZ, Ignacio Durendez; SALMERON, Bartolome Rios. La Obra cientifica de Manuel Alonso Olea: en sus XXV años de Catedrático de Derecho del Trabajo. Murcia: Editum, 1983.

MENDES, Marcus Menezes Barberino. Autonomia coletiva e a lei 13467/2017: apertem os cintos porque o garante do interesse público sumiu. Será? In: MAIOR, Jorge Luiz Souto; SEVERO, Valdete Souto. Resistência: aportes teóricos contra o retrocesso trabalhista. São Paulo: Expressão popular, 2017.

MILL, John Stuart. Ensayo sobre la libertad. Trad. María Ángeles Lavilla Navarro. Madrid: Miestas Ediciones, 2006.

MIRANDA, Pontes de. Democracia, liberdade e igualdade: os três caminhos. 2. ed. São Paulo: Saraiva, 1979.

NEVES, Maria do Céu Patrão. Sentidos da vulnerabilidade: característica, condição, princípio. In: Revista brasileira de bioética, vol.2, n.2, 2006, p. 157-172.

OITAVEN, Juliana Carreiro Corbal; CARELLI, Rodrigo de Lacerda; CASAGRANDE, Cássio Luís. Empresas de transporte, plataformas digitais e relação de emprego: um estudo do trabalho subordinado sob aplicativos. Brasília: Ministério Público do Trabalho, 2018.

PALOMEQUE, Manuel Carlos. Direito do trabalho e ideologia. Trad. Antônio Moreira. Coimbra: Almedina, 2001.

PENTEADO, Luciano de Camargo. Autonomia Privada E Negócios Jurídicos - Breves Notas. In: PUSCHEL, Flávia Portella. (Org.). Organização das relações privadas. São Paulo: Quartier Latin, 2007, v., p. 293-307.

WYZYKOWSKI, Adriana Brasil Vieira. Coronavírus e a farsa da liberdade negocial nos acordos individuais entre empregados e empregadores. Revista Jurídica Trabalho e Desenvolvimento Humano, Campinas, EDIÇÃO ESPECIAL - DOSSIÊ COVID-19, p. 1-25, 
Revista Jurídica Trabalho e Desenvolvimento Humano Procuradoria Regional do Trabalho da 15a Região

PINHEIRO, Armando Castelar; MATOS, Silvia. Boletim Macro abril 2020. Fundação Getúlio Vargas - Instituto Brasileiro de Economia (IBRE). Disponível em:

https://portalibre.fgv.br/data/files/BD/24/55/53/14CA1710199794F68904CBA8/BoletimMa crolbre 2004.pdf. Acesso em: 08 mai 2020.

PRATA, Ana. A tutela constitucional da autonomia privada. Lisboa: Almedina, 1982.

RAMALHO, Maria do Rosário Palma. Tratado de Direito do Trabalho. Parte I - Dogmática Geral. 3. ed. rev. e atual. Coimbra: Almedina, 2012.

RAWLS, John. Justiça e democracia. São Paulo: Martins Fontes, 2002.

ROSENVALD, Nelson. 0 direito civil em movimento: desafios contemporâneos. 2. ed., rev. e atual. Salvador: Juspodivm, 2018.

SARMENTO, Daniel. Os princípios constitucionais da liberdade e da autonomia privada. In: LEITE, George Salomão (org.). Dos princípios constitucionais: considerações em torno das normas principiológicas da Constituição. São Paulo: Malheiros, 2003.

SILVA, Luiz de Pinho Pedreira da. Principiologia do Direito do Trabalho. 2 ed. São Paulo: LTr, 1999.

STRECK, Lenio Luiz. Verdade \& Consenso: Constituição, Hermenêutica e teorias discursivas Da possibilidade à necessidade de respostas corretas no Direito. Rio de Janeiro: Lúmen Juris Editora, 2008.

SUPIOT, Alain. Crítica do Direito do Trabalho. Trad. Antônio Monteiro Fernandes. Lisboa: Fundação Calouste Gulbenkian, 2016.

WYZYKOWSKI, Adriana. Autonomia privada e vulnerabilidade do empregado: critérios para o exercício da liberdade negocial individual no Direito do Trabalho. Rio de Janeiro: Lumen Juris, 2019. 